\title{
Correction to: Surfen and oxalyl surfen decrease tau hyperphosphorylation and mitigate neuron deficits in vivo in a zebrafish model of tauopathy
}

Seyedeh Maryam Alavi Naini ${ }^{1,2}$, Constantin Yanicostas ${ }^{1}$, Rahma Hassan-Abdi ${ }^{1}$, Sébastien Blondeel ${ }^{1}$, Mohamed Bennis ${ }^{3}$, Ryan J. Weiss ${ }^{4}$, Yitzhak Tor ${ }^{4}$, Jeffrey D. Esko ${ }^{5}$ and Nadia Soussi-Yanicostas ${ }^{1 *}$

Correction to: Transl Neurodegener 7, 6 (2018)

https://doi.org/10.1186/s40035-018-0111-2

Following the publication of the original article [1], it was noted that due to a typesetting error several lines are mistakenly added in the Fig. 1 and they should be deleted.

The correct figure has been included in this correction, and the original article has been corrected.

\section{Author details}

'PROTECT, Inserm, Université Paris Diderot, Sorbonne Paris Cité, Paris, France. ${ }^{2}$ Institut de Biologie Paris Seine-Laboratoire Neuroscience Paris Seine, Inserm UMRS 1130, CNRS UMR 8246, UPMC UM 118, Université Pierre et Marie Curie, Paris, France. ${ }^{3}$ Cadi Ayyad University, Marrakesh, Morocco. ${ }^{4}$ Department of Chemistry and Biochemistry, University of California, San Diego, La Jolla, CA, USA. ${ }^{5}$ Department of Cellular and Molecular Medicine, University of California, San Diego, La Jolla, CA, USA.

Published online: 20 December 2020

\section{Reference}

1. Alavi Naini SM, et al. Surfen and oxalyl surfen decrease tau

hyperphosphorylation and mitigate neuron deficits in vivo in a zebrafish

model of tauopathy. Transl Neurodegener. 2018;7:6. https://doi.org/10.1186/ s40035-018-0111-2.

The original article can be found online at https://doi.org/10.1186/s40035 018-0111-2.

* Correspondence: nadia.soussi@inserm.fr

'PROTECT, Inserm, Université Paris Diderot, Sorbonne Paris Cité, Paris, France

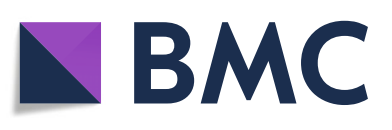

() The Author(s). 2020 Open Access This article is licensed under a Creative Commons Attribution 4.0 International License, which permits use, sharing, adaptation, distribution and reproduction in any medium or format, as long as you give appropriate credit to the original author(s) and the source, provide a link to the Creative Commons licence, and indicate if changes were made. The images or other third party material in this article are included in the article's Creative Commons licence, unless indicated otherwise in a credit line to the material. If material is not included in the article's Creative Commons licence and your intended use is not permitted by statutory regulation or exceeds the permitted use, you will need to obtain permission directly from the copyright holder. To view a copy of this licence, visit http://creativecommons.org/licenses/by/4.0/ The Creative Commons Public Domain Dedication waiver (http://creativecommons.org/publicdomain/zero/1.0/) applies to the data made available in this article, unless otherwise stated in a credit line to the data. 


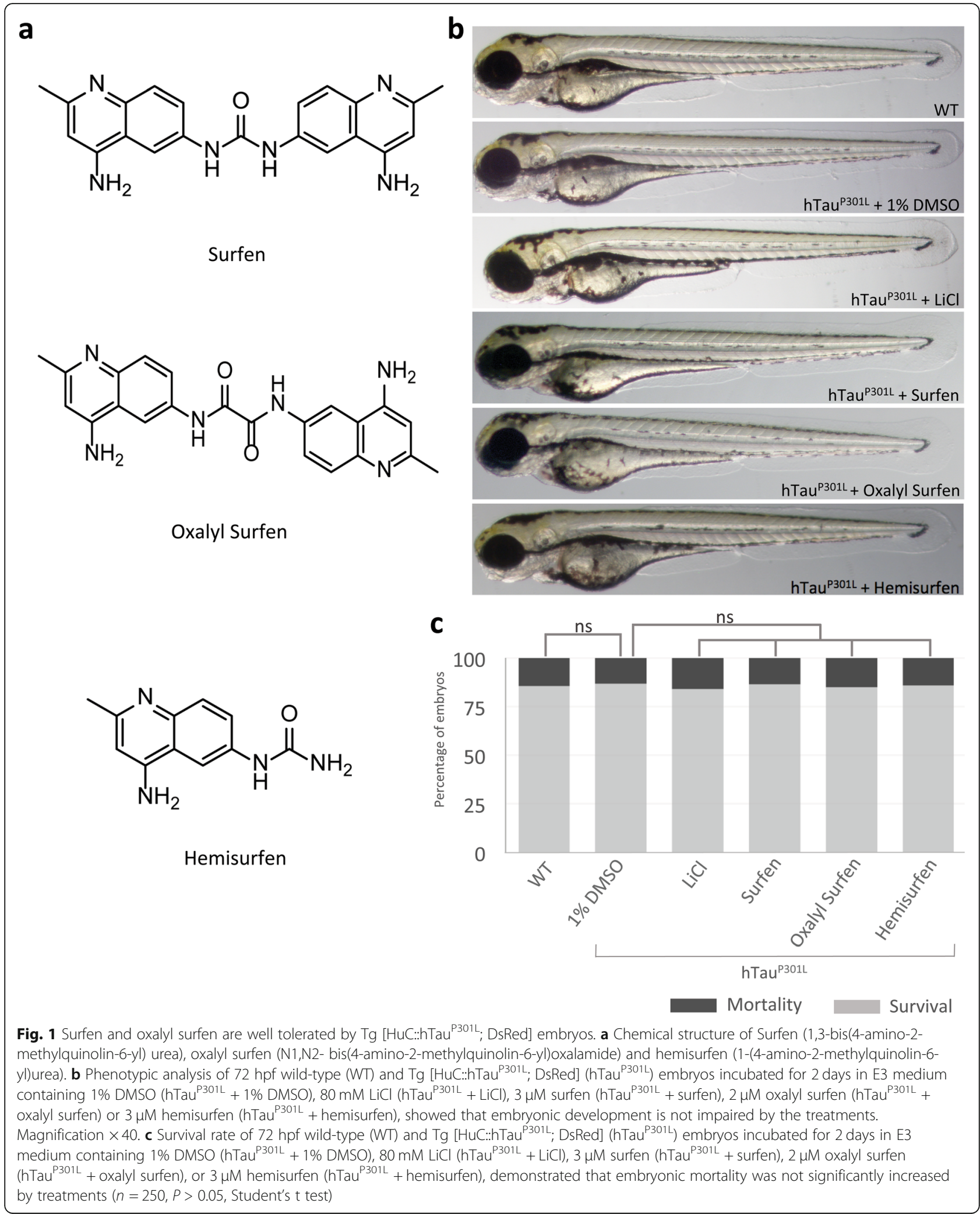

